\title{
ANP IN PERFORMANCE MEASUREMENT AND ITS APPLICATION IN A MANUFACTURING SYSTEM
}

\author{
Irem Ucal* \\ Istanbul Technical University \\ Istanbul Turkey \\ E-mail : iremucal@gmail.com \\ Başar Öztayşi \\ Istanbul Technical University, Istanbul Turkey \\ E-mail : oztaysib@itu.edu.tr
}

\begin{abstract}
As it is mentioned in the literature, performance measurement is a multi-perspective concept. For this reason, quantification of performance measurement can be modeled as a multi attribute decision problem. In this study, performance measurement is considered as an evaluation of the past activities with respect to the desired goals. With this definition, first a performance measurement system is proposed for a manufacturing system and an Analytical Network Process (ANP) technique is utilized in order to quantify the performance.
\end{abstract}

Keywords: performance measurement, analytical network process, manufacturing

\section{Introduction}

Performance is an efficiency measure with various measurement levels in itself while performance management is the development and improvement process based on the performance criteria defined on specifics of an institution or a firm. Performance measurement is defined as the process whereby an organization establishes the parameters within which programs, investments, and acquisitions are reaching the desired results (OCIO, 2007). It becomes more critical while improving performance through a better integration of operations across subsequent echelons and separate functions in the value chain became more important for the companies (Lohman, Fortuin, and Wouters, 2004).

According to Kaydos (1998), performance measures provide managers, front-line employees, and companies with a broad assortment of both cultural and technical benefits. These benefits go far beyond the bottom line, but they are not commonly recognized. While it is not a prerequisite to implementing performance measures, an understanding of these benefits will give managers insight into what makes a good measurement system and how performance measures should be used (Kaydos, 1998).

In performance measurement there exist lots of measurement models. The aim of this paper is to propose a performance measurement system by examining a manufacturing firm's performance using balanced score cards and analytical network process.

The rest of the paper is organized as follows. Literature reviews on performance measurement and analytical network process are given in Section 2. In Section 3, the methods used in the paper are

${ }^{*}$ Corresponding author 
represented. In Section 4, there is an application of the analytical network process on performance measurement of a manufacturing firm. In the last section we conclude the obtained results.

\section{Literature Review}

Ghalayini et al. (1997) represented an integrated dynamic performance measurement system developed in conjunction with a company. Mills at el. (2000) developed a framework for analyzing the implementation of a performance measurement system and used that framework to interpret three longitudinal case studies. Hudson et al (2001) described a research method to evaluate the appropriateness of strategic performance measurement system development processes for small- and medium-sized enterprises.

Chenhall (2005) identified a key dimension of strategic performance measurement systems, integrative information, as being instrumental in assisting managers deliver positive strategic outcomes. Parida and Kumar (2006) identified various issues and challenges associated with development and implementation of a maintenance performance measurement system. Henri (2006) tested the relationships between organizational culture and two attributes of performance measurement systems, namely the diversity of measurement and the nature of use.

Kim and Kim (2008) suggested a performance measurement framework called a customer relationship management scorecard to diagnose and assess a firm's customer relationship management practice. Chen (2009) modified the data envelopment analysis model to evaluate the performance of an enterprise, and showed that the available outputs of the modified model can be utilized to easily calculate the efficiencies of business units. Chin et al. (2009) presented a research using a K-user satisfaction based approach and evidential reasoning methodology to develop a user-satisfaction-based knowledge management performance measurement system for organizations to identify strengths and weaknesses, as well as enhance continuous learning.

\section{Methodology}

The method used in this study is Analytical Network Process. Saaty defines ANP as "The ANP is a theory of measurement generally applied to the dominance of influence among several stakeholders or alternatives with respect to an attribute or a criterion"(Saaty, 2001).

ANP has widespread usage in engineering applications. Saaty first found ANP in 1975 (Saaty, 2001). Gómez-Navarro et al. (2009) introduced a new approach to prioritize urban planning projects according to their environmental pressure in an efficient and reliable way, based on the combination of three procedures; the use of environmental pressure indicators, the aggregation of the indicators in an Environmental Pressure Index by means of the ANP and the interpretation of the information obtained from the experts during the decision-making process. Yazgan et al. (2009) developed an Artificial Neural Network model and trained it with using ANP results in order to calculate ERP software priority. Chang et al. (2009) developed a manufacturing quality yield model to forecast the 12 in silicon wafer slicing based on an ANP framework. Carlucci and Schiuma (2009) proposed a model, based on the ANP methodology, to disclose and assess how knowledge assets mutually interact and take part in company's value creation dynamics.

The first stage of ANP is to determine the decision problem and structuring it into a network. After structuring the problem, pairwise comparison matrices of interdependent component levels should be developed. Than supermatrix which represents the tool by determining global priorities in a network system, should be formed. The last stage is prioritization and selection of the alternative with the highest overall priority (Carlucci and Schiuma, 2009). 


\section{Application}

The goal is determined by experts as achieving corporate performance on a manufacturing company. The criteria of this goal are grouped into four perspectives which are customer, finance, learning \& growth of the organization and process.

The indicators of customer perspective are market share, customer complaints and market share. The indicators of finance are determined as productivity, return on investment (ROI) and cost reduction rate.

Labor training, time spent for continuous improvement and investment rate of improvement are the indicators of learning and growth perspective. Process criteria has five sub-criteria which are; flexibility, availability, delivery, speed and quality. Percentage of multipurpose equipment, load size and vendor lead time are defined as indicators for flexibility; percentage of machine uptime rate, usage of formalized preventive maintenance and ratio of maintenance cost repair are defined as indicators for delivery; set-up time, manufacturing lead time, cycle time and waiting time are defined as indicators for speed, and first pass yield, assembly line defects per hundred units and defects rate are defined as indicators for quality. The hierarchical structure is shown in Figure 1.

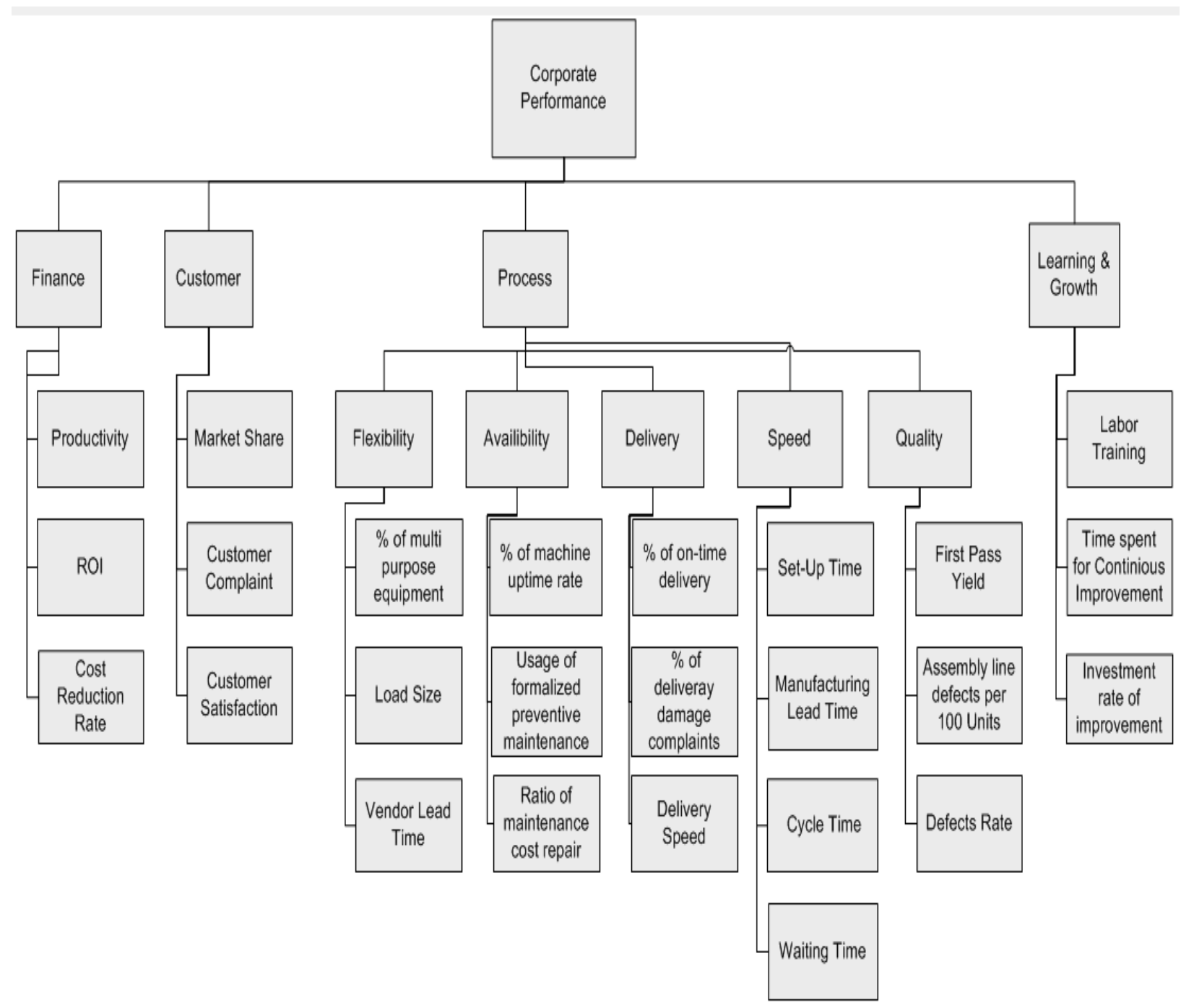

Figure 1. Hierarchical Structure 
After defining criteria and sub-criteria, the relations should be determined to learn whether the structure is a hierarchy or a network. Perspectives have an effect on each other as shown in Figure 2, so in this problem there is a network structure which can be solved by ANP methodology.

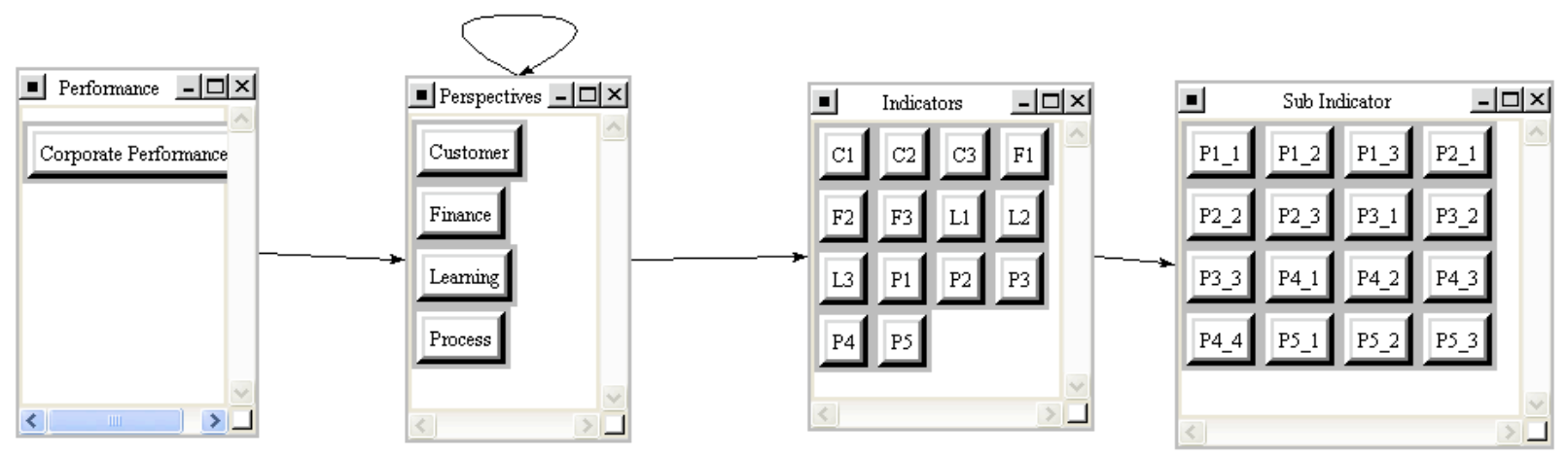

Figure 2. Relations on the structure

After building the structure, weights are calculated within the clusters. We used Super Decisions Software to calculate them. At the first step of weight calculations, perspectives are weighted by experts as shown in Table 1.

Table 1. Weights of the perspectives

\begin{tabular}{|l|l|}
\hline Perspectives & Weights \\
\hline Customer & 0,20781 \\
\hline Finance & 0,29338 \\
\hline Learning & 0,18885 \\
\hline Process & 0,30996 \\
\hline
\end{tabular}

Indicators and sub-indicators are weighted by experts respectively, and normalized points belong the clusters are given in Table 2 and 3.

Table 2. Weights of the indicators

\begin{tabular}{|l|l|}
\hline Indicators & Weights \\
\hline F1: Productivity & 0,617506 \\
\hline F2: ROI & 0,085641 \\
\hline F3: Cost Reduction Rate & 0,296854 \\
\hline C1: Market Share & 0,636964 \\
\hline C2: Customer Complaint (Daily) & 0,258287 \\
\hline C3: Customer Satisfaction & 0,104749 \\
\hline P1: Flexibility & 0,222506 \\
\hline P2: Availability & 0,126818 \\
\hline P3: Delivery & 0,650677 \\
\hline P4: Speed & 0,095044 \\
\hline P5: Quality & 0,116025 \\
\hline L1: Labor Training & 0,142874 \\
\hline L2: Time Spent On Cont. Improvements (Weekly Per Person) & 0,196187 \\
\hline L3: Investment Rate on Improvements & 0,44987 \\
\hline
\end{tabular}


Table 3. Weights of the sub-indicators

\begin{tabular}{|c|c|}
\hline Sub-indicators & Weights \\
\hline P1_1: \% Of Multi Purpose Equipment & 0,650642 \\
\hline P1_2: Lot Size & 0,222491 \\
\hline P1_3:Vendor Lead Time & 0,126867 \\
\hline P2_1: \% Of Machine Up Time Rate & 0,333333 \\
\hline P2_2: Usage Of Formalized Preventive & \\
Maintenance & 0,333333 \\
\hline P2_3: Ratio Of Maintenance Cost Repair & 0,333333 \\
\hline P3_1: \% Of On-Time Delivery & 0,600028 \\
\hline P3_2: \% Of Delivery Damage Complaints & 0,199986 \\
\hline P3_3: Delivery Speed & 0,199986 \\
\hline P4_1: Set-Up Time & 0,382761 \\
\hline P4_2: Manufacturing Lead Time & 0,086349 \\
\hline P4_3: Cycle Time & 0,099042 \\
\hline P4_4: Waiting Time & 0,431848 \\
\hline P5_1: First Pass Yield & 0,199996 \\
\hline P5_2: Assembly Line Defects Per 100 Units & 0,199996 \\
\hline P5_3: Defects Rate & 0,600009 \\
\hline
\end{tabular}

The weights of the indicators are applied to a manufacturing firm's data for two periods. Points for the periods are obtained with normalization of the values on the columns Period I and Period II on Table 4.

Table 4. Calculations

\begin{tabular}{|l|l|l|l|l|l|l|l|l|}
\hline & Weights & $\begin{array}{l}\text { Mea. } \\
\text { Unit }\end{array}$ & $\begin{array}{l}\text { Min } \\
\text { Value }\end{array}$ & $\begin{array}{l}\text { Max } \\
\text { Value }\end{array}$ & Period I & $\begin{array}{l}\text { Period I I } \\
\text { Point }\end{array}$ & $\begin{array}{l}\text { Period } \\
\text { II }\end{array}$ & $\begin{array}{l}\text { Period } \\
\text { II Point }\end{array}$ \\
\hline FINANCE & & & & & & & & \\
\hline F1: Productivity & 0,132367509 & $\%$ & $0 \%$ & $100 \%$ & $45 \%$ & 45,00 & $60,00 \%$ & 60,00 \\
\hline F2: ROI & 0,053674566 & $\%$ & $0 \%$ & $30 \%$ & $20 \%$ & 66,67 & $20,00 \%$ & 66,67 \\
\hline F3: Cost reduction rate & 0,021767925 & $\%$ & $0 \%$ & $10 \%$ & $3,00 \%$ & 30,00 & $3,50 \%$ & 35,00 \\
\hline CUSTOMER & & & & & & & & \\
\hline C1: Market share & 0,181163828 & $\%$ & $10 \%$ & $30 \%$ & $20 \%$ & 50,00 & $22,00 \%$ & 60,00 \\
\hline $\begin{array}{l}\text { C2: Customer complaint } \\
\text { (daily) }\end{array}$ & 0,025125278 & unit & 10 & 0 & 3 & 70,00 & 2 & 80,00 \\
\hline C3: Customer satisfaction & 0,087090894 & $\%$ & $0 \%$ & $100 \%$ & $75 \%$ & 75,00 & $80,00 \%$ & 80,00 \\
\hline PROCESS & & & & & & & & \\
\hline P1: Flexibility & & & & & & & & \\
\hline $\begin{array}{l}\text { P1_1: \% of multipurpose } \\
\text { equipment }\end{array}$ & 0,011678467 & $\%$ & $0 \%$ & $70 \%$ & $35 \%$ & 50,00 & $45,00 \%$ & 64,29 \\
\hline P1_2: Lot size & 0,003993526 & unit & 75 & 25 & 50 & 50,00 & 45 & 60,00 \\
\hline P1_3:Vendor lead time & 0,002277159 & day & 10 & 3 & 5 & 71,43 & 5 & 71,43 \\
\hline P2: Availability & & & & & & & & \\
\hline $\begin{array}{c}\text { P2_1: \% of machine up time } \\
\text { rate }\end{array}$ & 0,007303765 & $\%$ & $0 \%$ & $100 \%$ & $90 \%$ & 90,00 & $93,00 \%$ & 93,00 \\
\hline $\begin{array}{c}\text { P2_2: Usage of formalized } \\
\text { preventive maintenance }\end{array}$ & 0,007303765 & $\%$ & $0 \%$ & $100 \%$ & $75 \%$ & 75,00 & $80,00 \%$ & 80,00 \\
\hline
\end{tabular}


Table 4. Calculations (Cont.)

\begin{tabular}{|l|l|l|l|l|l|l|l|l|}
\hline & Weights & $\begin{array}{l}\text { Mea. } \\
\text { Unit }\end{array}$ & $\begin{array}{l}\text { Min } \\
\text { Value }\end{array}$ & $\begin{array}{l}\text { Max } \\
\text { Value }\end{array}$ & Period I & $\begin{array}{l}\text { Period I I } \\
\text { Point }\end{array}$ & $\begin{array}{l}\text { Period } \\
\text { II }\end{array}$ & $\begin{array}{l}\text { Period } \\
\text { II Point }\end{array}$ \\
\hline $\begin{array}{l}\text { P2_3: Ratio of maintenance } \\
\text { cost repair }\end{array}$ & 0,007303765 & $\%$ & $0 \%$ & $100 \%$ & $65 \%$ & 65,00 & $70,00 \%$ & 70,00 \\
\hline P3: Delivery & & & & & & & & \\
\hline P3_1: \% of on-time delivery & 0,016189761 & $\%$ & $0 \%$ & $100 \%$ & $85 \%$ & 85,00 & $90,00 \%$ & 90,00 \\
\hline $\begin{array}{l}\text { P3_2: \% of delivery damage } \\
\text { complaints }\end{array}$ & 0,005395957 & $\%$ & $100 \%$ & $0 \%$ & $20 \%$ & 80,00 & $15,00 \%$ & 85,00 \\
\hline P3_3: Delivery speed & 0,005395957 & day & 10 & 40 & 30 & 66,67 & 27 & 56,67 \\
\hline P4: Speed & & & & & & & & \\
\hline P4_1: Set-up time & 0,014181287 & hour & 16 & 3 & 6 & 76,92 & 5 & 84,62 \\
\hline $\begin{array}{l}\text { P4_2: Manufacturing lead } \\
\text { time }\end{array}$ & 0,003199241 & hour & 72 & 56 & 70 & 12,50 & 65 & 43,75 \\
\hline P4_3: Cycle time & 0,003669495 & hour & 7 & 2,5 & 5 & 44,44 & 3 & 88,89 \\
\hline P4_4: Waiting time & 0,015999982 & hour & 5 & 0 & 4 & 20,00 & 3,5 & 30,00 \\
\hline P5: Quality & & & & & & & & \\
\hline P5_1: First pass yield & 0,016991197 & $\%$ & $0 \%$ & $100 \%$ & $80 \%$ & 80,00 & $85,00 \%$ & 85,00 \\
\hline $\begin{array}{l}\text { P5_2: Assembly line defects } \\
\text { per 100 units }\end{array}$ & 0,016991197 & Unit & 40 & 0 & 18 & 55,00 & 14 & 65,00 \\
\hline P5_3: Defects rate & 0,050975479 & $\%$ & $0 \%$ & $2 \%$ & 0,03 & 150,00 & 0,03 & 150,00 \\
\hline LEARNING and GROWTH & & & & & & & & \\
\hline L1: Labor training & 0,068967807 & hour & 0 & 40 & 30 & 76,13 & 31 & 76,50 \\
\hline $\begin{array}{l}\text { L2: Time spent on cont. } \\
\text { improvements (weekly per } \\
\text { person) }\end{array}$ & 0,039308431 & hour & 2 & 6 & 4 & 50,00 & 4 & 37,50 \\
\hline $\begin{array}{l}\text { L3: Investment rate on } \\
\text { improvements }\end{array}$ & 0,201683762 & $\%$ & $0 \%$ & $15 \%$ & $5,00 \%$ & 33,33 & $7,00 \%$ & 46,67 \\
\hline
\end{tabular}

Finally, in Table 5 the improvements occurred among periods are calculated.

Table 5. Overall calculations

\begin{tabular}{|l|l|l|l|l|}
\hline & & $\begin{array}{l}\text { Period } \\
\text { Points }\end{array}$ & Period II Points & Improvement \\
\hline FINANCE & & 49,02497501 & 59,10318232 & 10,07820731 \\
\hline CUSTOMER & & 59,13415332 & 67,64988558 & 8,515732265 \\
\hline PROCESS & & 86,56466505 & 92,61554153 & 6,050876477 \\
\hline & P1: Flexibility & 52,71858375 & 64,23837576 & 11,51979201 \\
\hline & $\begin{array}{l}\text { P2: } \\
\text { Availability }\end{array}$ & 76,66666667 & 81 & 4,333333333 \\
\hline & P3: Delivery & 80,33365999 & 82,33386999 & 2,000209996 \\
\hline & P4: Speed & 43,56131819 & 57,92438241 & 14,36306423 \\
\hline & P5: Quality & 117,0007336 & 120,0006669 & 2,999933313 \\
\hline $\begin{array}{l}\text { LEARNING } \\
\text { GROWTH }\end{array}$ & & & & \\
\end{tabular}


The results show that significant improvements occurred in each perspective. Finance has the greatest improvement point where process has the least one. Company can decide the strategies among these improvement points easily.

\section{Conclusion}

Performance measurement systems have become more important with the globalization and increased competition. Institutions want to measure the improvements of their systems to easily take actions on the problematic departments or features immediately.

In this study we determined performance criteria and sub-criteria of a manufacturing firm. We used analytical hierarchy process to measure performance on a manufacturing firm's data and calculate the improvements occurred among two periods consecutively. In this method not only overall improvement points but also improvement points of criteria are obtained. With this functionality decision makers can find the root problems of their system.

As a further research, the performance criteria can be extended and this method can be applied to different sectors.

\section{REFERENCES}

Kaydos, W.J. (1998). Operational performance measurement: increasing total productivity, CRC Press.

Office of the Chief Information Officer (OCIO) Enterprise Architecture Program (2007). Treasury IT Performance Measures Guide, U.S. Department of the Treasury.

Bourne, M., Mills, J., Wilcox, M., Neely, A. \& Platts, K. (2000). Designing, implementing and updating performance measurement systems, International Journal of Operations \& Production Management, 20(7), , 754-771.

Henri, J.F. (2006). Organizational culture and performance measurement systems, Accounting, Organizations and Society, 31(1), 77-103.

Medori, D. \& Steeple, D. (2000). A framework for auditing and enhancing performance measurement systems, International Journal of Operations \& Production Management, 20(5), 520-533.

Ghalayini, A. M., Noble, J. S. (1997). An integrated dynamic performance measurement system for improving manufacturing competitiveness, International Journal of Production Economics, 48, 207-225.

Hudson, M., Smart, A. \& Bourne, M. (2001). Theory and practice in SME performance measurement systems, International Journal of Operations \& Production Management, 21(8), 1096-1115.

Lohman, C., Fortuin, L. \& Wouters, M. (2004). Designing a performance measurement system: A case study, European Journal of Operational Research, 156, 267-286.

Toni, A. D. and Tonchia, S. (2001). Performance measurement systems Models, characteristics and measures, International Journal of Operations \& Production Management, 21(1/2), 46-70. 
Chenhall, R. H. (2005). Integrative strategic performance measurement systems, strategic alignment of manufacturing, learning and strategic outcomes: an exploratory study, Accounting, Organizations and Society, 30, 395-422.

Parida, A. \& Kumar, U. (2006). Maintenance performance measurement (MPM): issues and challenges, Journal of Quality in Maintenance Engineering, 12(3), 239-251.

Chen, T. H. (2009). Performance measurement of an enterprise and business units with an application to a Taiwanese hotel chain, International Journal of Hospitality Management, 28(3), 415-422.

Chin, K. S., Lo, K. C. \& Leung, J. P. F. (2009) Development of User-Satisfaction-Based Knowledge Management Performance Measurement System with Evidential Reasoning Approach, Expert Systems with Applications, In Press, doi:10.1016/j.eswa.2009.05.051 .

Kim, H. S. \& Kim, Y. G. (2009), A CRM performance measurement framework: Its development process and application, Industrial Marketing Management, In Press, doi:10.1016/j.indmarman.2008.04.008 .

Gómez-Navarro, T., García-Melón, M., Acuña-Dutra, S. \& Díaz-Martín, D. (2009). An environmental pressure index proposal for urban development planning based on the analytic network process, Environmental Impact Assessment Review, 29(5), 319-329.

Yazgan, H. R., Boran, S. \& Goztepe, K. (2009). An ERP software selection process with using artificial neural network based on analytic network process approach, Expert Systems with Applications, 36(5), 9214-9222.

Carlucci, D. \& Schiuma, G. (2009). Applying the analytic network process to disclose knowledge assets value creation dynamics, Expert Systems with Applications, 36(4), 7687-7694.

Saaty, T. L. (2001). Decision Making with Dependence and Feedback: Decision Making With Dependence and Feedback, RWS Publications. 